\title{
Penerapan Model Waterfall dalam Pengembangan Sistem Informasi Akademik Berbasis Web sebagai Sistem Pengolahan Nilai Siswa
}

\author{
Sandra Melinda ${ }^{1}$, Ahmad Rifqi Maulana ${ }^{2}$, Kevin Fahrezi ${ }^{3}$, Nurhaliza $^{4}$, Sri Mulyati ${ }^{5}$ \\ Teknik Informatika, Universitas Pamulang, Tangerang Selatan, Indonesia, 15417 \\ e-mail: ${ }^{1}$ sandramelinda3105@gmail.com, ${ }^{2}$ rifqiahmad226@gmail.com, \\ ${ }^{3}$ kevinfahrezi0898@gmail.com, ${ }^{4}$ nurhalizathoirin@yahoo.com, ${ }^{5}$ dosen00391@unpam.ac.id \\ Submitted Date: April $06^{\text {th }}, 2021$ \\ Revised Date: July $05^{\text {th }}, 2021$ \\ Reviewed Date: April $11^{\text {th }}, 2021$ \\ Accepted Date: July 06 ${ }^{\text {th }}, 2021$
}

\begin{abstract}
In a school, teachers have difficulty managing student grades because they still use the manual method. The development carried out has the aim of creating a value management information system that will make it easier for teachers to manage student grades, because teachers need to handle student scoring activities which require a lot of time and require considerable accuracy. This information system will be applicable at the Vocational High School (SMK) level. This system is web-based, so that teachers can access the web for value management and students can also access the web to see the results of their learning. The development method applied to this development is by using the waterfall method. The results of this development are to facilitate and accelerate the performance of teachers in managing student grades in the school and become a benchmark for students so that students can understand their learning outcomes.
\end{abstract}

Keywords: Information Systems; Web-Based; Value Management

\begin{abstract}
Abstrak
Pada sebuah sekolah para guru kesulitan dalam mengelola nilai siswa karena masih menggunakan cara manual. Pengembangan yang dilakukan ini memiliki tujuan untuk menciptakan sebuah sistem informasi pengelola nilai yang akan mempermudah guru dalam mengelola nilai para siswa, karena guru perlu menangani kegiatan olah nilai siswa dengan membutuhkan banyak waktu dan membutuhkan ketelitian yang cukup besar. Sistem informasi ini akan dapat diaplikasikan pada jenjang Sekolah Menengah Kejuruan (SMK). Sistem ini berbasis web, sehingga guru dapat mengakses web untuk pengelolaan nilai dan siswa juga dapat mengakses web untuk lihat hasil pembelajarannya. Metode pengembangan yang diterapkan pada pengembangan ini yaitu dengan menggunakan metode waterfall. Hasil dari pengembangan ini adalah memudahkan dan mempercepat kinerja para guru dalam mengelola nilai siswa di sekolah tersebut serta menjadi tolak ukur bagi siswa agar siswa dapat memahami hasil belajarnya.
\end{abstract}

Kata Kunci: Sistem Informasi; Berbasis Web; Pengelolaan Nilai

\section{Pendahuluan}

Sistem informasi akademik berbasis internet memungkinkan akses mudah kepada guru dan siswa melalui browser di komputer atau telepon (Nurelasari, 2020). Pada sistem informasi akademik juga dapat mengolah data prestasi siswa dan menampilkan prestasi siswa terkini (Anam \& Muharram, 2018). Serta guru dan siswa dapat mengaksesnya di mana pun mereka berada.
Kebanyakan Sekolah Menengah Kejuruan (SMK) memproses nilai siswa menggunakan metode manual (Pane \& Sadar, 2015). Artinya, mereka menggunakan buku kerja atau aplikasi Excel sebagai ringkasan kinerja siswa. Jika memerlukan nilai untuk memproses transkrip atau memberikan nilai kepada siswa, ini kurang efisien karena mereka masih menggunakan metode tradisional. 
Permasalahan yang akan diselesaikan dengan pengembangan sistem informasi akademik ini adalah para guru yang sebelumnya masih menggunakan aplikasi Excel dalam melakukan pengolahan nilai siswa, yang dirasa tidak efisien pada pengisian nilai menggunakan data nilai yang begitu banyak. Kekurangan dalam penggunaan aplikasi Excel yang kurang user friendly dan kurang efisien untuk melakukan rekap nilai semester sebelumnya lantaran file tidak sama dan terkadang data yang terdapat dalam pengajar dan wali kelas dapat saja tidak sama misalnya nama atau nilai siswa lantaran penyimpanan data yang tidak sama. Oleh karenanya dibentuk sebuah solusi yang bisa mengoptimalkan kinerja pada pengolahan nilai yaitu menggunakan penggunaan sistem informasi akademik dengan penyimpanan data yang terintegrasi dan terpusat memakai basis data.

Pada pengembangan ini menggunakan model pengembangan waterfall. Model pengembangan waterfall merupakan model pengembangan yang sistematis dan berurutan (sekuensial). Waterfall memiliki tahapan pengembangan yaitu communication, planning, modeling, construction dan deployment.

Dengan bantuan pengembangan dan perancangan sistem informasi akademik ini yang akan dibangun dan ditujukan untuk melakukan kegiatan akademik yang terstruktur dan terintegrasi maka dapat digunakan bahasa pemrograman PHP yang terintegrasi dengan HTML, MySQL serta Apache. Sehingga dengan menyimpan data secara terpusat, dapat membuat mekanisme yang menggunakan teknologi komputer untuk mempermudah pengelolaan data.

Sistem informasi yang baik haruslah menampilkan informasi yang akurat dan telah dilakukan serangkaian pengujian (Ilham, Azmi, Ramadhani, Falah, \& Saifudin, 2021). Pengujian software untuk melakukan verifikasi dan validasi bahwa software yang telah dibuat sesuai dengan kebutuhan (Jaya, Gumilang, Wati, Andersen, \& Desyani, 2019). Sehingga sebelum diimplementasikan/digunakan, maka dilakukan pengujian terlebih dulu. Pada pengujian yang akan dilakukan digunakan metode black box. Metode pengujian black box adalah pengujian yang memverifikasi hasil eksekusi aplikasi berdasarkan masukan yang diberikan (data uji) untuk memastikan fungsional dari aplikasi sudah sesuai dengan persyaratan (requirement) (Febrian, Ramadhan, Faisal, \& Saifudin, 2020).

\section{Metodologi}

Pada pengembangan ini akan dibangun sistem informasi akademik berbasis web, guru serta siswa Sekolah Menengah Kejuruan (SMK) akan menggunakan sistem ini untuk kegiatan akademik. Dikembangkan sistem informasi akademik berbasis web karena dapat diakses lebih mudah dan tersebar lebih cepat sehingga lebih efisien (Yulianti, Saifudin, Haryono, Zulfikar, \& Desyani, 2020). Bagi guru untuk dapat mengoptimalkan kinerja dalam pengolahan nilai dan siswa dapat terus melacak dan menemukan nilai hasil pembelajaran yang dapat dilakukan di mana pun dan kapan pun (Suryandani, Basori, \& Maryono, 2017).

Metode yang digunakan untuk mengembangkan sistem informasi akademik ini adalah SDLC (System Development Life Cycle) dengan model waterfall. Dalam model ini, pengembangan sistem dibagi menjadi beberapa tahapan, yang dapat dijelaskan sebagai berikut:

a. Perencanaan (Planning)

Yaitu meliputi pengumpulan kebutuhan pada tingkat sistem, tingkat bisnis strategis, dan tingkat unit bisnis (misalnya, tingkat sistem). Melakukan studi kelayakan, alokasi waktu dan ruang lingkup sistem informasi untuk memantau perkembangan peserta didik.

b. Analisis (analysis)

Yaitu analisis dan alur kerja manajemen sistem yang sedang dijalankan. Analisis dilakukan dengan mengidentifikasi persyaratan aplikasi berdasarkan sistem yang sedang berjalan maupun harapan dari stakeholder.

c. Perancangan (design)

Yaitu termasuk desain alur kerja manajemen dan desain sistem informasi yang akan diimplementasikan. Gambar 1 adalah perancangan use case diagram Sistem Informasi Akademik berdasarkan persyaratan (requirement) yang telah ditetapkan. 


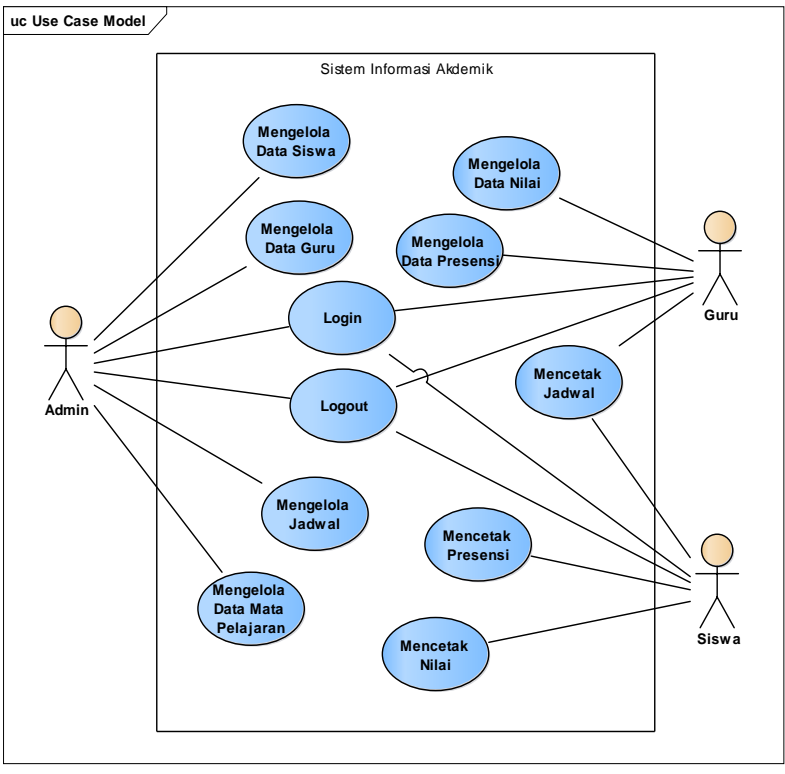

Gambar 1 Use Case Diagram Sistem Informasi Akademik

\section{d. Implementasi (implementation)}

Tahap ini disebut juga tahap pemrograman atau implementasi perangkat lunak. Tahap implementasi dilakukan dengan mengimplementasikan desain aplikasi yang dibuat menggunakan bahasa pemrograman sehingga menjadi aplikasi yang dapat dieksekusi. Hasil desain diwujudkan dalam bentuk string atau baris kode program yang dapat dipahami.

\section{e. Pengujian (testing)}

Pengujian perangkat lunak memiliki fungsi yang penting pada pengembangannya untuk menemukan galat (cacat) yang disebabkan oleh perbedaan antara hasil yang diharapkan dengan hasil sebenarnya (Pratama, Ristianto, Prayogo, Nasrullah, \& Saifudin, 2020). Pengujian sistem bertujuan untuk memastikan bahwa semua proses sudah berfungsi sesuai dengan kebutuhan yang ditetapkan (Muslimin, et al., 2020).

f. Pengoperasian dan Pemeliharaan (operation and maintenance)

Yaitu berarti mengambil Tindakan untuk mendukung pengoperasian sistem informasi akademik.

\section{Analisa kelayakan teknis, budaya, dan ekonomi \\ 1. Kelayakan Teknis \\ Kelayakan teknis mempertimbangkan}

persyaratan sistem dan mempertimbangkan aspek teknis yang akan digunakan saat membuatnya. Jika teknologi yang akan digunakan untuk mengembangkan sistem mudah digunakan, teknologi yang ada dapat digunakan dan tingkat pemanfaatannya sederhana. Kemudian persyaratan teknis dapat dinyatakan layak dijalankan.

2. Kelayakan Budaya

Tingkat pemanfaatan sistem. Informasi akademis berbasis web membutuhkan budaya akuisisi dan pembelajaran Kemandirian dan kebiasaan mengikuti perkembangan melalui komputer atau internet. Untuk menciptakan budaya belajar mandiri, harus menjadi milik semua pihak yang terlibat dalam proses sistem informasi akademik, seperti guru dan siswa.

3. Kelayakan Ekonomi

Kemampuan pengembangan sistem informasi akademik ini memiliki keunggulan, dengan demikian aspek untuk gagal menjadi pertimbangan utama dalam pengembangan sistem informasi ini. Kemungkinan dengan pengembangan sistem informasi akademik ini memiliki keuntungan karena dengan dibuatnya sistem informasi akademik akan menghemat penggunaan buku dalam pengelolaan nilai.

\section{Rencana dan rancangan pengembangan software}

Sistem informasi akademik sedang dibangun dan berkomitmen untuk melaksanakan kegiatan akademik terstruktur dan terintegrasi menggunakan bahasa pemrograman PHP yang berinteraksi dengan HTML, MySQL dan Apache. Oleh karena itu, gudang data pusat dapat membuat mekanisme yang memfasilitasi pengelolaan data dengan bantuan teknologi komputer. Sistem informasi akademik ini dikembangkan dengan menggunakan metode SDLC (System Development Life Cycle) dengan model waterfall. Waterfall memiliki beberapa tahapan yaitu planning, analysis, design, coding, implementation dan operation maintenance.

Pada tahapan planning akan dilakukan pengumpulan kebutuhan apa saja yang diperlukan oleh sistem, memperkirakan berapa besar biaya yang akan dibutuhkan untuk pengembangan ini, menjadwalkan kapan awal mulai dan selesai pengembangan dilakukan. Tahapan analysis akan 
dilakuan pengumpulan persyaratan inisiasi yaitu pengembangan seperti apa yang pelanggan (guru) inginkan untuk menggantikan sistem pengelolaan yang sebelumnya dengan manual.

Tahapan design akan dilakukan analisa pengembangan yang akan dilakukan akan bagaimana alurnya dan membuat desain seperti apa pengembangan itu akan dibuat. Tahapan coding dimulai untuk menjalankan proyek, yang dijalankan dengan serangkaian kode program yang dapat dipahami komputer. Pada tahap implementation akan dilakukan eksperimen untuk mengimplementasikan sistem yang telah dibangun agar dapat digunakan oleh pengguna. Tahap operation maintenance adalah kegiatan mendukung pengoperasian sistem informasi web dan memutakhirkan sistem informasi.

\section{Hasil dan Pembahasan}

\section{Tahap Perencanaan (Planning)}

Planning merupakan tahapan buat mendefinisikan suatu peta jalan (roadmap) buat mencapai tujuan. Pengembangan Sistem Informasi Akademik Berbasis Web Sebagai Sistem Pengolahan Nilai Siswa. Pada tahapan ini menghasilkan analisis mengenai kebutuhan sistem misalnya kebutuhan fungsional, kebutuhan aplikasi dan hardware menurut sistem.

\section{Tahap Analisis (Analysis)}

Pada tahapan analysis akan dilakuan pengumpulan persyaratan inisiasi secara detail yaitu pengembangan seperti apa yang pelanggan (guru) inginkan untuk menggantikan sistem pengelolaan yang sebelumnya dengan manual. Sehingga dapat dipahami sesuai dengan kebutuhan user.

\section{Tahap Perancangan (Design)}

Pada tahap design merupakan tahap contoh analisis untuk dapat memahami dengan lebih baik tentang sistem informasi akademik. Pada tahap ini akan dilakukan langkah seperti membuat rancangan usecase diagram yang akan menjadi tolak ukur untuk membuat sistem informasi akademik.

\section{Tahap Pemrograman (coding)}

Pada tahap ini sistem informasi akademik yang sudah selesai desain akan dibentuk menjadi suatu kode program yang sinkron menggunakan alur rancangan yang telah dibuat. Sehingga akan dihasilkan program sistem informasi akademik yang sinkron menggunakan desain tanpa terdapat error program.

- Halaman depan

Berikut adalah tampilan halaman login untuk para admin, guru dan siswa dapat masuk ke dalam halaman utama pada website.

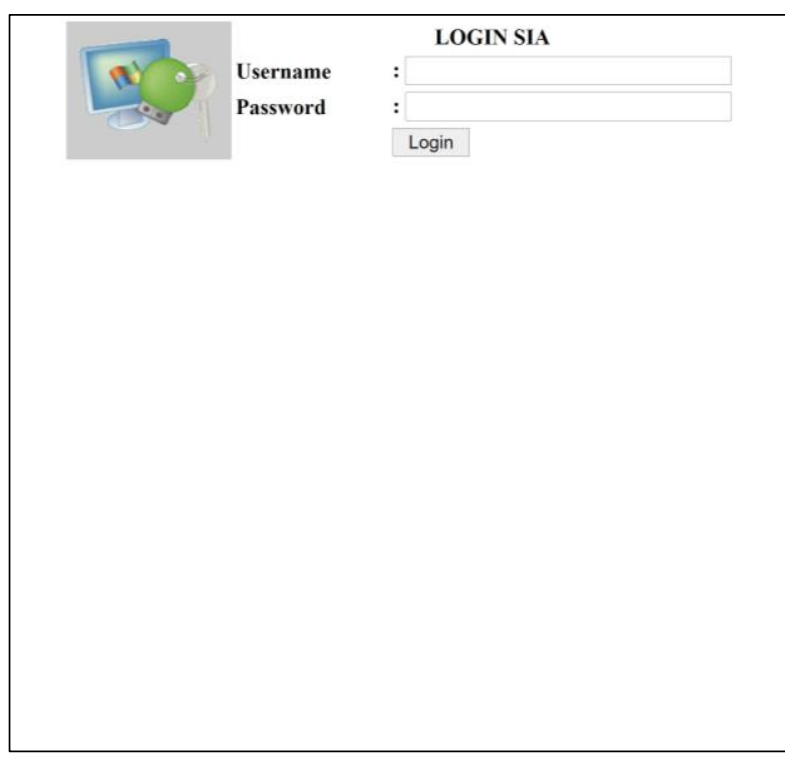

Gambar 2 Tampilan Form Login

- Tampilan menu utama

Berikut adalah tampilan halaman utama ketika admin sudah melakukan login pada website.

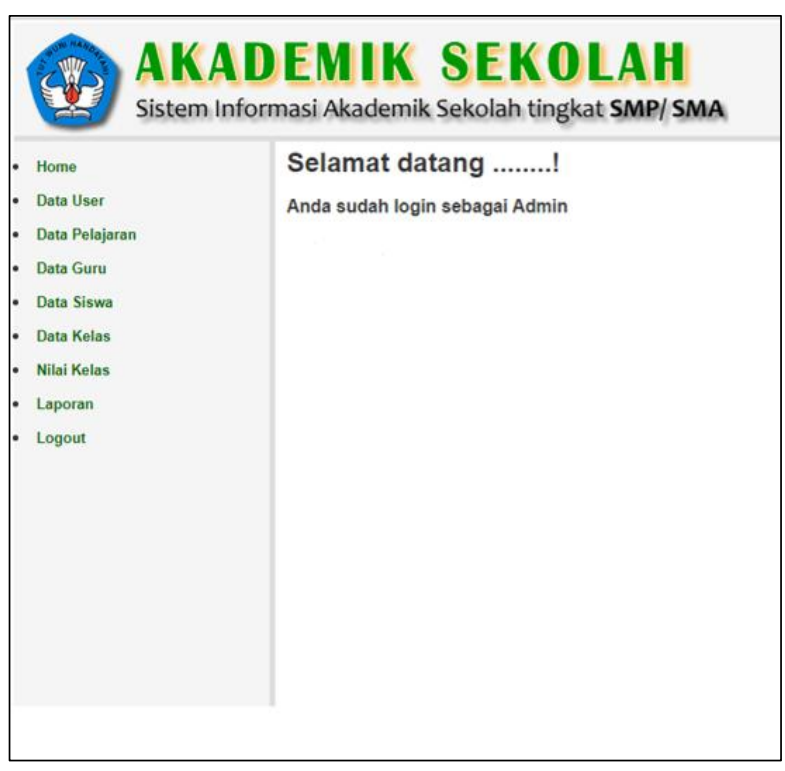

Gambar 3 Halaman Utama Sistem Informasi Akademik 


\section{Kesimpulan}

Sistem informasi akademik berbasis web menjadi sistem pengolahan nilai anak didik dikembangkan melalui enam tahap. Tahap pertama yaitu planning yang merupakan pengumpulan kebutuhan untuk sistem yang akan dikembangkan. Tahap kedua yaitu analysis membuat workflow manajemen sistem yang sedang berjalan. Tahap ketiga yaitu Design yang meliputi perancangan usecase. Tahap keempat adalah coding, yaitu tahap penerapan dari sistem yang sedang dikembangkan. Tahap kelima yaitu implementation yang merupakan penerapan sistem informasi yang sudah dibuat untuk digunakan user. Tahap keenam yaitu operation and maintenance yang merupakan kegiatan untuk mendukung beroperasinya web sistem informasi. Kelayakan dari sistem yang dikembangkan dilakukan pada tahap kelima yaitu tahap implementation.

\section{Saran}

Berikut adalah saran yang ada untuk pengembangan ini:

1. Perlu peningkatan dalam segi pengumpulan data analisis kebutuhan untuk mempermudah dalam mengimplementasikan ke dalam pengembangan sistem.

2. Peningkatan dalam pembuatan rancangan sehingga tidak hanya usecase saja.

3. Membuat tampilan sistem lebih menarik dan user friendly.

4. Perlu peningkatan pada pengembangan sistem informasi akademik menjadi lebih kompleks seperti adanya pendaftaran siswa baru, keuangan, perpustakaan online, serta fasilitas $e$ learning.

\section{Referensi}

Anam, K., \& Muharram, A. T. (2018, Oktober). Analisa dan perancangan sistem informasi akademik berbasis web pada mi al-mursyidiyyah al- ' asyirotussyafi , iyyah. JURNAL TEKNIK INFORMATIKA, I1(2), 207-217. doi:http://dx.doi.org/10.15408/jti.v11i2.8867

Febrian, V., Ramadhan, M. R., Faisal, M., \& Saifudin, A. (2020). Pengujian pada Aplikasi Penggajian
Pegawai dengan menggunakan Metode Blackbox. Jurnal Informatika Universitas Pamulang, $\quad 5(1), \quad 61-66$. doi:10.32493/informatika.v5i1.4340

Ilham, A. A., Azmi, A., Ramadhani, A. R., Falah, D. F., \& Saifudin, A. (2021). Pengujian Sistem Informasi Parkir PT KISP Berbasis Desktop dengan Metode Black-Box. Jurnal Informatika Universitas Pamulang, 6(1), 96-101. doi:10.32493/informatika.v6i1.8547

Jaya, M. S., Gumilang, P., Wati, T., Andersen, Y. P., \& Desyani, T. (2019). Pengujian Black Box pada Aplikasi Sistem Penunjang Keputusan Seleksi Calon Pegawai Negeri Sipil Menggunakan Teknik Equivalence Partitions. Jurnal Informatika Universitas Pamulang, 4(4), 131136. doi:10.32493/informatika.v4i4.3834

Muslimin, D. B., Kusmanto, D., Amilia, K. F., Ariffin, M. S., Mardiana, S., \& Yulianti, Y. (2020). Pengujian Black Box pada Aplikasi Sistem Informasi Akademik Menggunakan Teknik Equivalence Partitioning. Jurnal Informatika Universitas Pamulang, 5(1), 19-25. doi:10.32493/informatika.v5i1.3778

Nurelasari, E. (2020, April). Perancangan Sistem Informasi Akademik Pada Sekolah Menengah Pertama Berbasis Web. Komputika : Jurnal Sistem Komputer, 9(1), 67-73. doi:10.34010/komputika.v9i1.2243

Pane, E. S., \& Sadar, M. (2015). Rancangan Website Sistem Informasi Akademik Sekolah Menengah Kejuruan (SMK) Negeri 5 Pekanbaru. Jurnal Teknol, 6, 33-41.

Pratama, B. P., Ristianto, I. B., Prayogo, I. A., Nasrullah, \& Saifudin, A. (2020). Pengujian Perangkat Lunak Sistem Informasi Penilaian Mahasiswa dengan Teknik Boundary Value Analysis Menggunakan Metode Black Box Testing. Journal of Artificial Intelligence And Innovative Applications, 32-36.

Suryandani, F., Basori, \& Maryono, D. (2017, Januari). Pengembangan sistem informasi akademik berbasis web sebagai sistem pengolahan nilai siswa di smk negeri 1. Jurnal Ilmiah Pendidikan Teknik Kejuruan, 10(1), 71-82. doi:http://dx.doi.org/10.20961/jiptek.v10i1.14 976

Yulianti, Y., Saifudin, A., Haryono, W., Zulfikar, A. F., \& Desyani, T. (2020). Pengembangan dan Sosialisasi Website untuk Meningkatkan Penyebaran Informasi SMP Islam Madinatul I'lmi Ciputat-Tangerang Selatan. KOMMAS: Jurnal Pengabdian Kepada Masyarakat, 1(1), $16-24$ 